\section{State of Interventional Pain Medicine}

\author{
Laxmaiah Manchikanti, MD
}

"Every profession is a conspiracy against the laity," the famous playwright George Bernard Shaw once said. His observation, though fitting for some professions, does not describe the field of interventional pain medicine. In the last issue of Pain Physician, I explored various issues related to interventional pain medicine and interventional pain physicians (1). Despite a growing number of socalled "pain clinics" in the United States, organizations representing pain physicians and practitioners, and pain management journals, interventional pain medicine continues to suffer from a lack of proper recognition, as well as from misconceptions and malaise among interventional pain physicians. Of course, this is true for all specialties, as physicians are known to be reactive rather than proactive. Winston Churchill said, "True genius resides in the capacity for evaluation of uncertain and conflicting information." Interventional pain medicine is full of conflicting and uncertain information; however, the question remains: is there a true genius out there to sort out all these questions? This is not said with arrogance or with disrespect to pain specialists. However, pain medicine has been largely dominated and essentially taken over by physicians who believe in the biopsychosocial model, utilizing predominantly psychosocial approaches. While the biopsychosocial model is generally accepted and should be accepted by all interventional pain medicine specialists, we must also realize that the psychosocial approach is not the only way of managing these patients; interventions are an integral part of such an approach. Further, it has been stated by rulemakers in pain management that interventional pain medicine is a procedural specialty, rather than a field of pain medicine that is primarily a non-procedural specialty, and pain is always subjective and always a psychological state $(1,2)$. Of course, there

From Pain Management Center of Paducah, Paducah, Kentucky. Dr. Manchikanti is medical director of Pain Management Center of Paducah and President of Pain Management Anesthesiologists. Address correspondence: Laxmaiah Manchikanti, M.D., 2831 Lone Oak Road, Paducah, Kentucky 42003. Email: drm@apex.net is plenty of criticism of interventional pain medicine for excessive use and abuse of the interventions, lack of demonstration of medical necessity, lack of outcomes, and lack of cost effectiveness. This mostly anecdotal criticism, fair or unfair, not only stems from non-physicians, but also from physicians. More interestingly, much controversy stems from the inability of shortsighted pain specialists with differing philosophies and understanding of economics and medicine to assimilate facts and from overaggressive attitudes. This is not to say interventionalists are always above board. Thus, practice guidelines and the practice of conservative interventional medicine will go a long way in the new era of documentation and compliance.

It is beyond any question that neither pain management nor interventional pain medicine has specific recognition. While I was not surprised to find that interventional pain medicine has no recognition, I was somewhat taken aback to learn that pain management is generally not recognized as a specialty. Above all, I was shocked to see that specialists providing interventional pain medicine fall into 33 separate groups, as listed in Tables 1 and 2, though neither interventional pain medicine nor pain management makes the list. Pain management as a subspecialty is recognized by the American Board of Medical Specialties, which designates specialists from the three specialties of anesthesiology, physical medicine and rehabilitation, and neurology to qualify for subspecialty of pain management. Yet there is no subspecialty recognition for either pain management or interventional pain medicine by either public or private health care programs, such as Medicare, Medicaid, Blue Cross Blue Shield, AETNA, or United Health Care. In contrast, there is no shortage of subspecialty recognition by HCFA and others for multitude of others (Table 1). Thus, neurology and psychiatry have separate identities with psychiatrists having a subspecialty of neuropsychiatry. In radiology there are four specialty recognitions: diagnostic radiology, interventional radiology, radiation oncology, and nuclear medicine. In addition, recognition is offered to critical care medicine, preventive medicine, and emergency medi- 
Table 1. Provider specialty designations assigned by HCFA for multiple medical and surgical specialties

\begin{tabular}{|c|c|c|c|}
\hline $\begin{array}{l}\text { Numerical } \\
\text { Designation }\end{array}$ & Name Of Specialty & $\begin{array}{l}\text { Numerical } \\
\text { Designation }\end{array}$ & Name Of Specialty \\
\hline 01 & General practice & 37 & Pediatric medicine \\
\hline 02 & General surgery & 38 & Geriatric medicine \\
\hline 03 & Allergy/Immunology & 39 & Nephrology \\
\hline 04 & Otolaryngology & 40 & Hand surgery \\
\hline 05 & Anesthesiology & 41 & Optometry \\
\hline 06 & Cardiology & 44 & Infectious disease \\
\hline 07 & Dermatology & 46 & Endocrinology \\
\hline 08 & Family practice & 48 & Podiatry \\
\hline 10 & Gastroenterology & 66 & Rheumatology \\
\hline 11 & Internal medicine & 76 & Peripheral vascular disease \\
\hline 12 & Osteopathic manipulative therapy & 77 & Vascular surgery \\
\hline 14 & Neurosurgery & 78 & Cardiac surgery \\
\hline 16 & Obstetrics/Gynecology & 79 & Addiction medicine \\
\hline 18 & Ophthalmology & 81 & Critical care \\
\hline 19 & Oral surgery (dentists only) & 82 & Hematology \\
\hline 20 & Orthopedic surgery & 83 & Hematology/Oncology \\
\hline 22 & Pathology & 84 & Preventive medicine \\
\hline 24 & Plastic \& reconstructive surgery & 85 & Maxillofacial surgery \\
\hline 25 & Physical medicine rehabilitation & 86 & Neuropsychiatry \\
\hline 26 & Psychiatry & 90 & Medical oncology \\
\hline 28 & Colorectal surgery & 91 & Surgical oncology \\
\hline 29 & Pulmonary disease & 92 & Radiation oncology \\
\hline 30 & Diagnostic radiology & 93 & Emergency medicine \\
\hline 33 & Thoracic surgery & 94 & Interventional radiology \\
\hline 34 & Urology & 98 & Gynecological oncology \\
\hline 35 & Chiropractor & 99 & Unknown physician specialty \\
\hline 36 & Nuclear medicine & & \\
\hline
\end{tabular}

cine. Further, general practice can be identified as general practice, family practice, internal medicine, and osteopathy. Of course, multiple internal medicine subspecialties include geriatric medicine, nephrology, infectious diseases, endocrinology, cardiology, pulmonology, rheumatology, preventive medicine, hematology, hematology/oncology, addiction medicine and critical care medicine. In addition, numerous surgical specialties include a multitude of subspecialties. This shows the gravity of the situation with regards to the non-recognition of pain management in general and interventional pain medicine in particular, especially in the face of the recognition of addiction medicine, critical care medicine, neuropsychiatry, and various radiological subspecialties.
Recognition of a specialty is an extremely important aspect of the practice of medicine for reimbursement purposes as practice relative values are developed separately for each recognized specialty. Practice expense values for most interventional procedures are derived from anesthesiology, even though a large proportion of the procedures is performed by other specialists. In fact, hourly practice expense data for all physicians is $\$ 68$, dermatology is $\$ 115$, pathology is $\$ 47$, neurology is $\$ 59$, physical medicine rehabilitation is $\$ 88$, in contrast ti aneshestology practice expense per hour of $\$ 27$ as per physician fee schedule. Lack of subspecialty recognition also results in lack of representation on Medicare carrier committees. At the present time, the three specialties — anesthesiology, physical medicine and rehabilitation - and neurol- 
Table 2. Frequency of utilization of lumbar epidural injections (CPT 62311) by various specialties for 1998, in Medicare population

\begin{tabular}{|c|c|c|c|c|}
\hline \multirow{3}{*}{$\begin{array}{l}\text { Specialty } \\
\text { Nurse practitioners }\end{array}$} & \multicolumn{4}{|c|}{ No. of Procedures } \\
\hline & Facility & Office & Total & \\
\hline & & 10 & 0 & 10 \\
\hline Urology & & 0 & 15 & 15 \\
\hline Radiation oncology & & 15 & 0 & 15 \\
\hline OB/GYN & & 11 & 17 & 28 \\
\hline Endocrinology & & 0 & 29 & 29 \\
\hline Gastroenterology & & 0 & 30 & 30 \\
\hline Cardiology & & 37 & 0 & 37 \\
\hline Pathology & & 0 & 43 & 43 \\
\hline Nuclear Medicine & & 51 & 0 & 51 \\
\hline Oral surgery(dentists only) & & 0 & 68 & 68 \\
\hline Preventive medicine & & 74 & 0 & 74 \\
\hline Nephrology & & 0 & 84 & 84 \\
\hline Critical Care & & 86 & 0 & 86 \\
\hline Allergy/Immunology & & 121 & 0 & 121 \\
\hline Ambulatory surgery center & & 160 & 0 & 160 \\
\hline Thoracic surgery & & 14 & 150 & 164 \\
\hline Osteopaths & & 439 & 48 & 487 \\
\hline Psychiatry & & 181 & 352 & 533 \\
\hline Emergency medicine & & 543 & 103 & 646 \\
\hline Interventional radiology & & 1162 & 0 & 1162 \\
\hline General surgery & & 1135 & 383 & 1518 \\
\hline Rheumatology & & 287 & 1245 & 1532 \\
\hline Family practice & & 1804 & 957 & 2761 \\
\hline General practice & & 1816 & 1359 & 3175 \\
\hline Internal medicine & & 2175 & 1898 & 4073 \\
\hline Neurology & & 3126 & 3582 & 6708 \\
\hline Neurosurgery & & 5587 & 1672 & 7259 \\
\hline Clinic or other group & & 7068 & 1823 & 8891 \\
\hline CRNA/AA* & & 9511 & 644 & 10155 \\
\hline Diagnostic radiology & & 6506 & 4547 & 11053 \\
\hline Physiatry & & 16461 & 7112 & 23573 \\
\hline Orthopedic surgery & & 12350 & 14569 & 26919 \\
\hline Anesthesiology & & 445048 & 51563 & 496611 \\
\hline Total & & 515778 & 92293 & 608071 \\
\hline
\end{tabular}

Source: HCFA utilization file 1998

*CRNA/AA Certified Registered Nurse Anesthetist/Anesthesia Assistant

ogy are represented, in many cases, on local Medicare carrier review committee with issues of interventional pain medicine being represented by the anesthesiology representative. In approximately $90 \%$ of the cases, the anesthesiologist, who is also a representative of the State So- ciety of Anesthesiologists, practices anesthesiology, and at best, practices pain management on an occasional or part-time basis. Thus, interventional pain medicine basically has no representation as anesthesiology representatives are mostly concerned with operating room anes- 
thesia and, specifically in recent years, with the issue of nurse anesthetists and supervision by anesthesiologists. This should not underrate any of the issues represented by these professionals, but the fact remains that interventional pain medicine basically does not have any representation.

The next issue is who is practicing interventional pain medicine? A recent review of utilization statistics for 1998 provided by HCFA for all types of services also includes specific involvement of the specialties in providing interventional pain procedures. For the purpose of this review, I considered anesthesiologists, physical medicine rehabilitation specialists, and neurologists practicing pain management as interventional pain practitioners. The remaining groups were considered as non-pain practitioners, even though orthopedic surgeons, neurosurgeons, interventional radiologists, and diagnostic radiologists performed a number of interventional pain procedures. As per the American Board of Medical Specialties, these specialties are not recognized for subspecialty in pain management. Similarly, these physicians are not practicing pain as their primary subspecialty and their interests mainly revolve, not only around their specialty, but also around the diagnostic aspects of pain rather than total interventions related to pain. One of the surprising results of the 1998 utilization of procedures on Medicare recipients showed that HCFA has decided to utilize 2000 codes for 1998, codes which were not available at the time or even proposed by extrapolating or cross-walking some of the procedures actually performed in 1998. Thus, while many of the epidural codes are grouped together into one epidural code, statistics are also available, whether they accurately represent the prevalence of these procedures or not, for epidural lysis of adhesions (CPT 62263), cervical and thoracic facet joint nerve blocks (CPT 64470 and CPT 64472), cervical and thoracic facet neurolysis (CPT 64626 and CPT 64627), cervical/thoracic transforaminal epidurals (CPT 64479 and CPT 64480), lumbosacral transforaminal epidural injections (CPT 64483 and CPT 64484), and sacroiliac joint injections. As shown in Table 2, lumbar epidural injections are performed mainly by 33 specialties, with anesthesiologists doing the procedures most frequently, followed by orthopedic surgeons, physical medicine and rehabilitation physicians, diagnostic radiologists, certified registered nurse anesthetists, procedures performed in a clinic or other group practices, neurosurgery, and neurology. As shown in Table 2, a substantial number of procedures are also performed by physicians practicing internal medicine, general practice, family practice, and rheumatology. Surprisingly, epidural injections were performed by emergency room physicians, psychiatrists, osteopaths, thoracic surgeons, allergy/immunology physicians, critical care medicine physicians, nephrologists, preventive medicine physicians, dentists practicing oral surgery, cardiologists, urologists, and nurse practitioners.

Even more surprising than the performance of epidural injections is the evidence demonstrated for trigger point and various types of joint injections (Table 3). Approximately $75 \%$ of trigger point injections were performed by non-pain physicians. Understandably, intraarticular injections are performed mainly by non-pain physicians.

Table 3. Frequency of utilization of trigger point injections and intraarticular injections by pain management and other specialties for year 1998, in Medicare population

\begin{tabular}{|c|c|c|c|c|c|c|c|c|c|c|c|c|}
\hline & & \multicolumn{2}{|c|}{ Anesthesiology } & \multicolumn{2}{|c|}{ Neurology } & \multicolumn{2}{|c|}{ Physiatry } & \multicolumn{2}{|c|}{ Others } & \multicolumn{2}{|c|}{ Total } & \multirow[b]{2}{*}{ Total } \\
\hline & & Facility & Office & Facility & Office & Facility & Office & Facility & Office & Facility & Office & \\
\hline 20550 & $\begin{array}{l}\text { Trigger point } \\
\text { injection }\end{array}$ & 105383 & 94016 & 1911 & 31507 & 6559 & 74505 & 24663 & 850232 & 138516 & 1050260 & 1188776 \\
\hline 20600 & $\begin{array}{l}\text { Small joint } \\
\text { injection }\end{array}$ & 1508 & 821 & 14 & 214 & 196 & 2117 & 7796 & 402133 & 9514 & 405285 & 414799 \\
\hline 20605 & $\begin{array}{l}\text { Intermediate } \\
\text { joint injection }\end{array}$ & 3520 & 1993 & 52 & 660 & 780 & 5823 & 16940 & 438277 & 21292 & 446753 & 468045 \\
\hline 20610 & $\begin{array}{l}\text { Large joint } \\
\text { injection }\end{array}$ & 30523 & 15853 & 61 & 2230 & 4102 & 26070 & 102417 & 2288918 & 137103 & 2333071 & 2470174 \\
\hline 27096 & $\begin{array}{l}\text { Sacro-iliac joint } \\
\text { injection }\end{array}$ & 276 & 16 & 0 & 0 & 57 & 12 & 1719 & 294 & 2052 & 322 & 2374 \\
\hline Total & & 141210 & 112699 & 2038 & 34611 & 11694 & 108527 & 153535 & 3979854 & 308477 & 4235691 & 4544168 \\
\hline
\end{tabular}

Source: HCFA utilization file 1998 
Table 4. Frequency of utilization of various types epidural spinal and disc injection procedures in Medicare population for 1998, by pain management and other specialties

\begin{tabular}{|c|c|c|c|c|c|c|c|c|c|c|c|c|}
\hline & & \multicolumn{2}{|c|}{ Anesthesiology } & \multicolumn{2}{|c|}{ Neurology } & \multicolumn{2}{|c|}{ Physiatry } & \multicolumn{2}{|c|}{ Others } & \multicolumn{2}{|c|}{ Total } & \multirow[b]{2}{*}{ Total } \\
\hline & & Facility & Office & Facility & Office & Facility & Office & Facility & Office & Facility & Office & \\
\hline 62263 & Epidural lysis of adhesions & 661 & 84 & 0 & 10 & 19 & 0 & 203 & 24 & 883 & 118 & 1001 \\
\hline 62280 & Subarachnoid neurolysis & 161 & 21 & 0 & 0 & 0 & 0 & 44 & 0 & 205 & 21 & 226 \\
\hline 62281 & Cervical epidural neurolysis & 1266 & 225 & 23 & 62 & 0 & 0 & 53 & 65 & 1342 & 352 & 1694 \\
\hline 62282 & Lumbar epidural neurolysis & 4343 & 1349 & 83 & 286 & 246 & 1124 & 862 & 1180 & 5534 & 3939 & 9473 \\
\hline 62290 & Lumbar discography & 1928 & 337 & 66 & 55 & 258 & 111 & 4022 & 2007 & 6274 & 2510 & 8784 \\
\hline 62291 & Cervical discography & 355 & 226 & 15 & 0 & 0 & 19 & 620 & 137 & 990 & 382 & 1372 \\
\hline 62310 & Cervical/Thoracic epidural & 50442 & 6848 & 352 & 444 & 1121 & 329 & 3411 & 1616 & 55326 & 9237 & 64563 \\
\hline 62311 & Lumbar/Sacral epidural & 445048 & 51538 & 3126 & 3582 & 16461 & 7112 & 51143 & 30036 & 515778 & 92268 & 608046 \\
\hline 62318 & Cervical continuous epidural & 3517 & 514 & 23 & 12 & 93 & 19 & 154 & 50 & 3787 & 595 & 4382 \\
\hline 62319 & Lumbar continuous epidural & 108790 & 298 & 151 & 34 & 92 & 16 & 7275 & 210 & 116308 & 558 & 116866 \\
\hline Total & & 616511 & 61440 & 3839 & 4485 & 18290 & 8730 & 67787 & 35325 & 706427 & 109980 & 816407 \\
\hline
\end{tabular}

Source: HCFA utilization file 1998

As shown in Table 4, a substantial number of procedures $-76,517$, or $9 \%$ of 816,417 , epidural injections, subarachnoid injections, epidural lysis of adhesions, and discography - were performed by non-pain physicians. However, the statistics become blurry as we proceed to facet joint blocks and facet joint neurolysis, of which 62,057 , or $23 \%$ of 270,437 , were performed by non-pain physicians (Table 5). Since a substantial number of these procedures are performed by physicians with no training in pain management and in office settings, the issue of

Table 5. Frequency of utilization of facet joint injections and neurolytic blocks in Medicare population for 1998, by pain management and other specialities

\begin{tabular}{|c|c|c|c|c|c|c|c|c|c|c|c|c|}
\hline & & \multicolumn{2}{|c|}{ Anesthesiology } & \multicolumn{2}{|c|}{ Neurology } & \multicolumn{2}{|c|}{ Physiatry } & \multicolumn{2}{|c|}{ Others } & \multicolumn{3}{|c|}{ Total } \\
\hline & & Facility & Office & Facility & Office & Facility & Office & Facility & Office & Facility & Office & Total \\
\hline 64470 & $\mathrm{C} / \mathrm{T}$ facet joint block - single & 2978 & 592 & 54 & 192 & 238 & 305 & 788 & 1139 & 4058 & 2228 & 6286 \\
\hline 64472 & $\mathrm{C} / \mathrm{T}$ facet joint block - additional & 264 & 34 & 0 & 0 & 0 & 0 & 51 & 0 & 315 & 34 & 349 \\
\hline 64475 & $\begin{array}{l}\text { Lumbar/Sacral facet joint block - } \\
\text { single }\end{array}$ & 39593 & 7963 & 717 & 2561 & 3207 & 4079 & 11040 & 15547 & 54557 & 30150 & 84707 \\
\hline 64476 & $\begin{array}{l}\text { Lumbar/Sacral facet joint block - } \\
\text { additional }\end{array}$ & 84233 & 16512 & 1074 & 1579 & 6218 & 5293 & 15650 & 13524 & 107175 & 36908 & 144083 \\
\hline 64622 & L/S facet neurolysis - single & 7229 & 1037 & 117 & 21 & 256 & 260 & 1108 & 343 & 8710 & 1661 & 10371 \\
\hline 64623 & L/S facet neurolysis - additional & 18289 & 1976 & 196 & 29 & 719 & 242 & 2257 & 559 & 21461 & 2806 & 24267 \\
\hline 64626 & $\mathrm{C} / \mathrm{T}$ facet neurolysis - single & 25 & 0 & 0 & 0 & 0 & 0 & 0 & 0 & 25 & 0 & 25 \\
\hline 64627 & $\mathrm{C} / \mathrm{T}$ facet neurolysis - additional & 264 & 34 & 0 & 0 & 0 & 0 & 51 & 0 & 315 & 34 & 349 \\
\hline Total & & 152875 & 28148 & 2158 & 4382 & 10638 & 10179 & 30945 & 31112 & 196616 & 73821 & 270437 \\
\hline
\end{tabular}

Source: HCFA utilization file 1998 
correct coding will justifiably show its ugly head in this case. Subsequently, in Table 6, which shows the number of various nerve blocks (other than the ones described above), performed on Medicare recipients during 1998 it is shown that 211,282 , or $50 \%$ of 423,942 , procedures were performed by non-pain physicians and many of them in the offices and by physicians with no formal or informal training in interventional pain medicine. Finally, Table

Table 6. Frequency of utilization of various types of nerve blocks excluding epidurals, disc injections, and facet joint blocks in Medicare population for 1998, by pain management and other specialists

\begin{tabular}{|c|c|c|c|c|c|c|c|c|c|c|c|c|}
\hline & & \multicolumn{2}{|c|}{ Anesthesiology } & \multicolumn{2}{|c|}{ Neurology } & \multicolumn{2}{|c|}{ Physiatry } & \multicolumn{2}{|c|}{ Others } & \multicolumn{2}{|c|}{ Total } & \multirow[b]{2}{*}{ Total } \\
\hline & & Facility & Office & Facility & Office & Facility & Office & Facility & Office & Facility & Office & \\
\hline 64400 & Trigeminal N.B. & 2695 & 680 & 31 & 369 & 87 & 526 & 597 & 4092 & 3410 & 5667 & 9077 \\
\hline 64402 & Facial N.B. & 466 & 275 & 0 & 54 & 0 & 48 & 916 & 764 & 1382 & 1141 & 2523 \\
\hline 64405 & Greater occipital N.B. & 8255 & 3316 & 295 & 5611 & 170 & 1004 & 692 & 5405 & 9412 & 15336 & 24748 \\
\hline 64408 & Vagus N.B. & 0 & 0 & 0 & 78 & 0 & 0 & 0 & 180 & 0 & 258 & 258 \\
\hline 64410 & Phrenic N.B. & 35 & 0 & 0 & 0 & 0 & 0 & 0 & 0 & 35 & 0 & 35 \\
\hline 64412 & Spinal accessory N.B. & 322 & 268 & 0 & 63 & 0 & 83 & 0 & 402 & 322 & 816 & 1138 \\
\hline 64413 & Cervical plexus block & 1162 & 1187 & 12 & 445 & 18 & 261 & 142 & 3820 & 1334 & 5713 & 7047 \\
\hline 64415 & Brachial plexus block & & & & & & & & & 0 & 0 & 0 \\
\hline 64417 & Axillary N.B. & 1090 & 330 & 0 & 103 & 0 & 53 & 73 & 101 & 1163 & 587 & 1750 \\
\hline 64418 & Suprascapular N.B. & 2241 & 2110 & 0 & 379 & 12 & 559 & 94 & 4348 & 2347 & 7396 & 9743 \\
\hline 64420 & Intercostal & 2943 & 812 & 17 & 152 & 25 & 152 & 419 & 3474 & 3404 & 4590 & 7994 \\
\hline 64421 & Intercostal N. Blocks & 11280 & 2911 & 16 & 174 & 64 & 269 & 1445 & 3326 & 12805 & 6680 & 19485 \\
\hline 64425 & Ilio-Inguinal N.B. & 2599 & 891 & 0 & 95 & 38 & 82 & 405 & 1 & 3042 & 1069 & 4111 \\
\hline 64430 & Pudendal N.B. & 163 & 114 & 0 & 0 & 0 & 0 & 121 & 1447 & 284 & 1561 & 1845 \\
\hline 64435 & Paracervical N.B. & 43 & 17 & 0 & 0 & 0 & 0 & 271 & 1622 & 314 & 1639 & 1953 \\
\hline 64445 & Sciatic N.B. & 2170 & 3688 & 10 & 2256 & 40 & 2092 & 288 & 9677 & 2508 & 17713 & 20221 \\
\hline 64450 & Peripheral N.B. & 14487 & 11478 & 159 & 2250 & 842 & 2642 & 6020 & 90026 & 21508 & 106396 & 127904 \\
\hline 64479 & $\mathrm{C} / \mathrm{T}$ transforaminal epidural - single & 759 & 291 & 10 & 218 & 76 & 230 & 264 & 1444 & 1109 & 2183 & 3292 \\
\hline 64480 & $\begin{array}{l}\mathrm{C} / \mathrm{T} \text { transforaminal epidural - each } \\
\text { additional }\end{array}$ & 3094 & 2247 & 45 & 901 & 329 & 1587 & 351 & 8512 & 3819 & 13247 & 17066 \\
\hline 64483 & LS transforaminal - single & 10087 & 3923 & 181 & 2914 & 1010 & 3145 & 3954 & 20161 & 15232 & 30143 & 45375 \\
\hline 64484 & L/S transforaminal - each additional & 9304 & 6756 & 134 & 2702 & 985 & 4759 & 1223 & 19675 & 11646 & 33892 & 45538 \\
\hline 64505 & Sphenopalatine ganglion block & 407 & 379 & 0 & 20 & 27 & 71 & 56 & 5562 & 490 & 6032 & 6522 \\
\hline 64510 & Stellate ganglion block & 10014 & 1618 & 29 & 183 & 141 & 54 & 340 & 589 & 10524 & 2444 & 12968 \\
\hline 64520 & Lumbar/Thoracic sympathetic block & 9352 & 501 & 0 & 523 & 102 & 544 & 551 & 1823 & 10005 & 3391 & 13396 \\
\hline 64530 & Celiac plexus block & 1164 & 175 & 16 & 0 & 0 & 0 & 183 & 0 & 1363 & 175 & 1538 \\
\hline 64600 & Trigeminal neurolysis & 283 & 23 & 0 & 29 & 21 & 37 & 121 & 221 & 425 & 310 & 735 \\
\hline 64605 & Trigeminal neurolysis & 107 & 45 & 0 & 0 & 0 & 0 & 32 & 25 & 139 & 70 & 209 \\
\hline 64610 & Trigeminal neurolysis & 112 & 0 & 20 & 0 & 0 & 0 & 461 & 0 & 593 & 0 & 593 \\
\hline 64613 & $\begin{array}{l}\text { Chemodenervation cervical spinal } \\
\text { muscle }\end{array}$ & 372 & 90 & 2075 & 12478 & 118 & 276 & 368 & 829 & 2933 & 13673 & 16606 \\
\hline 64620 & Intercostal neurolysis & 1408 & 192 & 0 & 0 & 12 & 0 & 93 & 47 & 1513 & 239 & 1752 \\
\hline 64630 & Pudendal nerve neurolysis & 16 & 0 & 0 & 0 & 0 & 0 & 0 & 0 & 16 & 0 & 16 \\
\hline 64640 & Peripheral neurolysis & 3947 & 770 & 910 & 2209 & 2170 & 3600 & 1021 & 2748 & 8048 & 9327 & 17375 \\
\hline 64680 & Celiac plexus neurolysis & 767 & 71 & 0 & 0 & 101 & 0 & 190 & 0 & 1058 & 71 & 1129 \\
\hline Total & & 101144 & 45158 & 3960 & 34206 & 6388 & 22074 & 20691 & 190321 & 132183 & 291759 & 423942 \\
\hline
\end{tabular}

Source: HCFA utilization file 1998 
Table 7. Summary of frequency of utilizations of various categories interventions in Medicare population for 1998, by pain management and other specialists

\begin{tabular}{|c|c|c|c|c|c|c|c|c|c|c|c|}
\hline & \multicolumn{2}{|c|}{ Anesthesiology } & \multicolumn{2}{|c|}{ Neurology } & \multicolumn{2}{|c|}{ Physiatry } & \multicolumn{2}{|c|}{ Others } & \multicolumn{2}{|c|}{ Total } & \multirow[b]{2}{*}{ Total } \\
\hline & Facility & Office & Facility & Office & Facility & Office & Facility & Office & Facility & Office & \\
\hline Epidural, spinal, and disk injections & 616511 & 61440 & 3839 & 4485 & 18290 & 8730 & 67787 & 35325 & 706427 & 109980 & 816407 \\
\hline Facet joint blocks & 152875 & 28148 & 2158 & 4382 & 10638 & 10179 & 30945 & 31112 & 196616 & 73821 & 270437 \\
\hline Other types of nerve blocks & 101144 & 45158 & 3960 & 34206 & 6388 & 22074 & 20691 & 190321 & 132183 & 291759 & 423942 \\
\hline Total & 870530 & 134746 & 9957 & 43073 & 35316 & 40983 & 119423 & 256758 & 1035226 & 475560 & 1510786 \\
\hline
\end{tabular}

7 shows the summary of epidural, spinal, and disc injections; facet joint blocks, including neurolysis; and all other types of nerve blocks, obviously excluding trigger-point injections and joint injections that 376,181 , or $25 \%$ of $1,510,786$, were performed by non-pain physicians with a substantial number in office setting, once again raising the questions of legitimacy and accuracy of these procedures.

These facts demonstrate the sad reality of present and proposed coverage for interventional pain medicine if practiced on a legitimate basis with appropriate performance. HCFA, in its ambulatory surgery center proposed rule, eliminated all interventional pain medicine procedures, except for epidural and subarachnoid injections. Subsequently, HCFA also agreed to incorporate multiple new CPT codes into the fee schedule of physicians, as well as hospital outpatients for interventional pain procedures (3-6). Unfortunately, these codes were not extended to ambulatory surgery centers. In a program memorandum it issued, HCFA delineated certain services with replacement codes for pain management procedures but refused to include new procedures based on various technical limitations. We have been told that these services, which include percutaneous lysis of adhesions, transforaminal epidural injections, cervical facet joint nerve blocks, and neurolytic blocks, simply are not available to ambulatory surgery center patients, pending the final implementation of the ASC final rule in April 2001. However, even if HCFA does approve these new procedures and incorporate them into ambulatory surgery center approved procedure listing at a later date, the process would, we fear, take about three years. If HCFA publishes a new rule for ASCs in 2000, with an implementation date of April 2001, the next publication for a proposed rule would likely be in the year 2002, with final publication and its implementation sometime in 2002 or even 2003. It is the responsibility of all concerned to address the issue of fairness of these proposals, not only to ambulatory surgery centers, but, more importantly, to Medicare beneficiaries.

Now the question is are these so-called new codes really new? As literature dictates, a number of CPT 2000 pain management codes are just replacement codes for the other codes (ex. epidural injection codes) (3). It is surprising to note the definitions of new, replacement, revised, and substitution in Webster's Dictionary of the English Language. New is defined as "made, discovered, known, heard or seen for the first time." Replacement is defined as "replacing or being replaced." Revised is defined as "to reexamine, especially in order to discover and amend errors." Finally, substitute is defined as "a person or thing taking the place of another person or thing." In addition, synonyms for new include: modern, late, recent, contemporary, fresh, current, original, imaginative, creative, unique, authentic, unexampled, unfamiliar, strange, unusual, unheard of, extraordinary, unused, unhandled, untouched, unexplored, untested, unknown, untried, and experimental. Further, these synonyms also include: refreshed, renewed, restored, reinvigorated, revivified, reborn, regenerated, changed, rebuilt, recreated, reconstructed, and modernized. Thus, the family of codes, which are branded as new codes by American Medical Association and Health Care Financing Administration, essentially do not fit the description of new; rather, they fit the definitions of replacement, revised, and substitute. The emphasis should be laid on the fact that these procedures were, even though recorded for the first time, not discovered for the first time, not heard of for the first time, not seen for the first time, not known for the first time, and definitely not created for the first time; rather, a numerical number was awarded for these procedures for the first time. 


\section{Lumbar Transforaminal Epidural Injections (CPT Codes 64483 and 64484)}

The earliest use of epidural steroids was surprisingly by a transforaminal route (7-17). This involved transforaminal passage of a needle through first dorsal sacral foramen in order to gain access to the first sacral nerve roots. The procedure was popularized in the 1950 s by various authors $(7,8)$. Following this, lumbar transforaminal epidural steroid injections were developed. Three approaches available to access the epidural space in the lumbar area are lumbar interlaminar, caudal, and transforaminal. The perceived disadvantages of interlaminar epidural injections include:

- Extradural placement or placement of the needle outside the epidural space goes unrecognized without fluoroscopic guidance and occurs in as many as $35 \%$ of patients (18-23).

- The erroneous missing of the targeted interspace by one or two levels without fluoroscopic guidance, specifically in the thoracic or lumbar regions $(19,23,24)$.

- The possible necessity to position the needle one level below the site of suspected pathology due to preferential cranial flow of solutions in the epidural space $(19,24,25)$.

- The possible deviation of the needle toward the nondependent side. Difficulty may be encountered with the placement or delivery of the injection or medication below L5 for S1 nerve root involvement, an issue with nearly half of all disc herniations (19, 22, 26-28).

- The potential trauma of the needle to the spinal cord may become a major issue in the upper lumbar regions (29-31).

- The potential risks of dural puncture and postdural puncture, headache, as well as total spinal block are significant with interlaminar epidural injections $(19,20)$.

Similar to the interlaminar entry, there are significant complications and risks associated with a caudal epidural injection approach through sacral hiatus:

- There is a need to inject high volumes of fluid into the epidural space, creating the potential for serious complications (19-21, 32).

- Similar to interlaminar lumbar epidural injections, unrecognized placement of the needle outside the epidural space is seen in a substantial number of cases, in perhaps as many as $35 \%$ of patients (18-20, 22, 23, 32-36).

All of these disadvantages are essentially eliminated with a transforaminal epidural injection (18-20, 3744). Transforaminal epidurals are considered to be the precise and preferred route of delivery of the medication to the target site for the following reasons:

- The other two approaches of lumbar interlaminar or caudal epidural steroids do not guarantee that whatever drug is injected will reach the perceived or involved target site.

- Once a drug is injected into the epidural space, the operator has no control over its dispersal, which is governed by the pressure of the injection, the amount or volume of the injection, and the anatomy of the epidural space.

- Normal epidural ligaments and epidural scarring may obstruct the passage of medication from reaching the desired site.

The main or cardinal site of inflammation or pathology is the interface between the back of an intervertebral disc and the front of the dural sac or a nerve root sleeve. It is extremely unusual and difficult to reach this point with interlaminar or caudal epidural injections.

- The appropriate injection is, by contrast, delivered exactly to this location with a transforaminal epidural approach.

- With other approaches, the physician is totally at the mercy of the epidural anatomy and the resistance to spread that will determine whether or not the medication will pass around to the front of the dural sac and produce the desired effect.

Lumbar and sacral transforaminal epidural injections have long been performed by physicians practicing interventional pain techniques. However, these procedures have been coded utilizing the lumbar epidural injection codes, with or without steroids, CPT codes 62278 or 62289. The statistics HCFA has derived from ambulatory surgery centers, hospitals, and offices showing the number of epidural injections performed in these settings includes transforaminal injections. Essentially, the transforaminal epidural injection is just another approach similar to interlaminar lumbar and caudal epidural steroid injections, procedures that HCFA concedes it must offer in an ASC setting. The idea that transforaminal injections are not covered, when other approaches to the 
same epidural space are covered is, in our view, indefensible.

Significantly, the codes at issue were cross-walked to lumbar facet injection codes, 64442 and 64443 . These are precisely the codes that HCFA acknowledged in the program memorandum that are covered, of course, with replacement codes 64475 and 64476. In assigning the relative values for these codes, RUC and HCFA used the reimbursement values for lumbar epidural injections.

Above all, review of 1998 utilization data showed that a significant number of procedures were performed utilizing CPT code 64483 and CPT code 64484. We are not sure how this data was derived. We suspect that the deleted codes for lumbar paravertebral nerve blocks 64440 single, and 64441 multiple, were used to convert these. Apparently this conversion does not reflect either the crosswalk used by AMA, RUC, and HCFA, or the definition and description of transforaminal epidural codes, which is a great disservice. In addition, CPT code 64483 is described as a transforaminal lumbar or sacral epidural, which always requires $\mathrm{x}$-ray visualization for accuracy (accuracy will be less than $1 \%$ without $x$-ray). The same description applies for CPT 64484 with the same limitations. HCFA's 1998 statistics show, rather unfortunately, that the procedure has been mislabeled, with statistics yielding a large number of procedures. These statistics should not be utilized for transforaminal injections. These staggering numbers show that of 45,395 procedures for CPT 64480, only 47\%, or 21,280, were performed by interventional pain specialists with subspecialty recognition, namely, anesthesiology, physical medicine rehabilitation, and neurology; whereas 24,115 were performed by non-pain management specialists. Surprisingly, a great number were performed by general practitioners, family practitioners, internists, and rheumatologists in their offices. Unfortunately, the same statistics are true for CPT 64484. However, this essentially indicates HCFA's willingness to accept the so-called "new coding" to incorporate the old coding, even though it is inaccurate. Still, this does not explain HCFA's reluctance to do the right thing and include these codes in the program memorandum as approved procedures for ambulatory surgical centers.

\section{Cervical Transforaminal Epidural Injections (CPT Codes 64479 and 64480)}

The information provided for lumbar/sacral transforaminal epidural injections also applies to cervical transforaminal epidural injections. Cervical transforaminal epidural injections have long been employed. Because the complication rate is much higher for interlaminar cervical epidural injections, with or without fluoroscopy, than it is for transforaminal epidural injections, it is a disservice to Medicare beneficiaries to not provide coverage for this service, which has a lower risk for complications $(18,45-48)$.

Cervical transforaminal epidural injections are not a new procedure and have long been billed, based on guidance from various carriers, under cervical epidural injection using CPT code 62275 ; this code has been substituted by CPT 62310. In addition, HCFA was also liberal in providing approval for an ASC code for ambulatory surgery center setting, 62318, which is a continuous cervical epidural with catheter placement, a code that was not present in the previous surgical center approved listing. Once again, the statistics HCFA has derived from ambulatory surgical centers, hospitals, and offices showing the number of epidural injections performed in these settings includes transforaminal injections. Essentially, the transforaminal epidural injection is just another approach that is similar to interlaminar cervical epidural injections, procedures that HCFA considers it must offer in an ASC setting. Once again, the idea that transforaminal injections will not be covered while other approaches to the same epidural space are covered is indefensible.

Significantly, the codes at issue were cross-walked to lumbar facet injection codes, 64442 and 64443 . These are precisely the codes that HCFA acknowledged in the program memorandum that are covered, of course, with replacement codes 64475 and 64476. In assigning the relative values for these codes, RUC and HCFA used the reimbursement values for lumbar epidural injections.

Above all, review of 1998 utilization data showed a significant number of procedures were performed utilizing CPT code 64479 and CPT code 64480. Unfortunately, the misconceptions of CPT 64483 and 64484 were carried to CPT 64479 and 64480.

\section{Cervical Facet Joint Nerve Blocks and Cervical Facet Joint Neurolysis (CPT Codes, 64470, 64472, 64626, and 64627)}

Like lumbar facet joint mediated pain with its approved codes, cervical facet joint mediated pain and its treatments have been used widely for several years. Cervical pain syndromes are some of the most common patient com- 
plaints. They include neck pain, headaches, and arm pain similar to low back and lower extremity pain (48). The first discussion of facet joint as a potential source of neck pain, headache, or upper extremity pain emerged in 1986 and 1988, with facet joint injections themselves described in the 1970s (48-51).

The rationale for diagnostic neural blockade in the management of neck pain stems from the following facts:

- No clinical features, imaging, or neurophysiologic studies permit the accurate diagnosis of causation of neck pain and referred pain.

- Structural and morphological changes do not predict levels of pain or disability.

- The cervical facet joints have been shown capable of being a source of neck pain and referred pain in the head or upper extremity and normal volunteers.

- Controlled studies have shown that among patients with chronic neck pain after whiplash, for which no other cause is evident, the prevalence of cervical facet joint pain is significant.

- The existence of cervicogenic headache originating from various structures in the neck (4966).

Based on the present literature, facet joint mediated pain may be the single most common source of chronic pain and perhaps one of the most overlooked diagnoses in medicine.

Similarly, the rationale for facet joint nerve blocks and neurolysis for therapeutic purposes is based on a multitude of considerations:

- The cardinal source of neck pain - namely facet joints, atlanto-axial and atlanto-occipital joints — are accessible to facet joint blocks and neurolysis.

- Correction of structural abnormalities of the cervical spine may fail to cure and, at times, may even worsen painful conditions.

- Degenerative processes of the cervical spine and the origin of the spinal pain are extremely complex phenomenon.

- Failure of a multitude of interventions to show effectiveness unequivocally.

Further, the rationale is also based on the philosophy that if a particular joint is determined to be the source of pain generation, long-term relief can be sought by directing intervention or treatment at that joint. In fact, long-term improvement has been reported from the anesthetic and corticosteroid injections into the facet joints, or by denervation of the medial branches $(18,48,51,55-59)$. Various studies describing injections of facet joints, medial branch blocks, and radio frequency neurotomy have been very encouraging $(18,48,51,58-72)$.

Historically, cervical facet joint injections and cervical facet joint neurolysis have been performed for as long as lumbar facet joint injections and lumbar facet joint neurolysis, if not longer. The lumbar facet joint injection and lumbar facet joint neurolysis codes were used to cover injections in the cervical spine with a cervical spine diagnosis based upon guidance from Medicare carriers.

The 2000 codes are not "new codes." The AMA simply expanded the existing definitions and provided a code with a new number. Cervical facet joint injections and cervical facet neurotomy are significantly effective in managing neck pain, as well as headaches and upper extremity pain. They should not be denied to Medicare beneficiaries.

Once again, the codes at issue are cross-walked to lumbar facet joint injection codes 64442 and 64443 and lumbar facet neurolysis codes 64475 and 64476. These are precisely the codes that HCFA acknowledged in the program memorandum as the codes that are covered, with, of course, replacement codes 64475 and 64476 for lumbar facet joint injections, whereas neurolytic codes remained the same. Assigning the relative values for these codes, RUC and HCFA used the reimbursement values for lumbar facet joint injections and lumbar neurolysis procedures.

Above all, review of 1998 utilization data showed a significant number of procedures were performed utilizing CPT codes 64470, 64472, 64626, and 64627. The majority of these were performed in facility settings. While we are not aware of the conversion criteria used by HCFA in this utilization file, these numbers show that cervical facet joint injections were performed using CPT codes 64470 and 644726,746 times, with 4,433 of these performed in facility settings $(66 \%)$ and the remainder in non-facility settings. Similarly, CPT codes 64626 and 64627 for cervical facet neurolysis were used on 374 occasions, with 34 of these procedures performed in facility settings (91\%) and the remainder performed in non-facility settings (Table 8). This essentially indicates HCFA's willingness 
Table 8. The utilization statistics for proposed deleted procedures based on utilization data on Medicare recipients by HCFA for 1998

\begin{tabular}{llrrrrr}
\hline & & \multicolumn{4}{c}{ Number of Procedures } \\
\cline { 3 - 6 } CPT & Description & \multicolumn{3}{c}{ Facility } & \multicolumn{3}{c}{ Non-facility } \\
\cline { 3 - 5 } & Number & Percent & Number & Percent & Total \\
\hline 64420 & Intercostal nerve block, single & 3,404 & 42.9 & 4,536 & 57.1 & 7,940 \\
64421 & Intercostal nerve block, multiple & 12,688 & 65.6 & 6,659 & 34.4 & 19,347 \\
64475 & L/S facet joint block, single level & 54,557 & 64.4 & 30,150 & 35.6 & 84,707 \\
64476 & L/S facet joint block, each additional level & 107,175 & 74.4 & 36,908 & 25.6 & 144,083 \\
64622 & L/S facet neurolysis, single level & 8,710 & 84 & 1,661 & 16 & 10,371 \\
64623 & L/S facet neurolysis, each additional level & 21,461 & 88.4 & 2,806 & 11.6 & 24,267 \\
64510 & Stellate ganglion block & 10,524 & 81.2 & 2,444 & 8.8 & 12,968 \\
64520 & Lumbar/thoracic sympathetic block & 10,005 & 74.8 & 3,368 & 25.2 & 13,373 \\
64530 & Celiac plexus block & 1,363 & 88.6 & 175 & 11.4 & 1,538 \\
64605 & Trigeminal neurolysis & 139 & 66.5 & 70 & 33.5 & 209 \\
64610 & Trigeminal neurolysis & 593 & 100 & 0 & 0 & 593 \\
64620 & Intercostal neurolysis & 1,513 & 86.4 & 2390 & 13.6 & 1,752 \\
64680 & Celiac plexus - neurolysis & 1,058 & 93.7 & 71 & 6.3
\end{tabular}

to accept the so-called "new coding" to incorporate into the old coding. However, this does not explain HCFA's reluctance to include these codes in the program memorandum as approved procedures for ambulatory surgical centers. Once again, we would like to emphasize that these do not reflect actual numbers, since the majority probably are included or incorporated with CPT codes 64475, 64476, 64622, and 64623, which describe lumbar facet injections and neurolytic blocks.

\section{Percutaneous Lysis of Adhesions (CPT Code 62263)}

Percutaneous lysis of epidural adhesions has been performed since the early 1990s by pain management practitioners. Based on guidance from Medicare carriers, the procedure was reimbursed under CPT code 62282, a lumbar neurolysis code or lumbar plexus neurolysis code. The procedure has been shown to be clinically effective, demonstrating cost effectiveness with safety when performed in an outpatient surgical setting (73-78).

Percutaneous lysis of adhesions has been performed since the 1970s. Significantly, the code at issue was cross-walked to 62282 , which is the code that precisely continues to be approved for ambulatory surgery centers. In assigning the relative value for this code, RUC and HCFA used the reimbursement value for 62282 , which is a lumbar neurolytic code, even though the definition has been revised for 2000 .

Above all, review of 1998 utilization data showed a significant number of procedures were performed utilizing CPT code 62282. The majority of these were performed in a facility setting. While we are not aware of the conversion criteria utilized by HCFA in this utilization file, these numbers show that the number of times percutaneous lysis of adhesions was performed utilizing CPT 62263 was 1,001 , with 883 of these performed in facility settings $(88 \%)$ and the remainder in non-facility settings. Similarly, CPT code 62282, the old code for lysis of adhesions, was used on 9,473 occasions, with 5,534 of these performed in facility settings and the remainder in nonfacility settings. Once again this is an indication of HCFA's willingness to accept the so-called "new coding" to incorporate the old coding. Again, this does not explain HCFA's reluctance to include this code in the program memorandum as approved procedures for ambulatory surgical centers.

Surprisingly, though, the present list of approved ambulatory surgical center procedures includes some procedures that are neither indicated nor utilized to a level to be re- 
ported in the statistics, as some are performed infrequently. These include phrenic nerve block (CPT 64410), pudendal nerve block (CPT 64430), neurolysis of pudendal nerve (CPT 64630), axillary nerve block (CPT 64417), brachial plexus block (CPT 64415), drainage of spinal fluid (CPT 62272), cervical/thoracic continuous epidural (CPT 62318), cervical/sacral continuous epidural (CPT 62319), and lumbar epidural neurolytic injection (CPT 62282).

Further, 1998 utilization statistics also were in favor of interventional pain medicine specialists to do these procedures in a facility setting. This is not to say that these should not be performed in an appropriate office setting, but to reiterate that they should not be coded as such unless the procedure was performed appropriately with demonstrated medical necessity. As shown in Table 8, all the procedures, except for intercostal nerve, single level (CPT 64420), were largely performed the in facility settings, indicating that they should be retained as ASC-approved procedures.

In summary, review of 1998 utilization data shows some dangerous trends, with many of the procedures performed nearly $50 \%$ of the time by non-pain specialists, including general practice, family practice, internal medicine physicians; certified registered nurse anesthetists; and nurse practitioners. Thus, the dangers of either inappropriate coding, as well as medical necessity and quality of care provided in these situations, is of paramount concern. This will become much more apparent and prevalent since paravertebral nerve block codes CPT 64440 and 64441 have been deleted from CPT coding 2000, thus leading practitioners to code either deep trigger-point injections or other types of injections as facet joint injections. Thus, interventional pain medicine is not only on an un-level playing field, but also at a substantial disadvantage due to unclear and, at best, ambiguous regulations that will only take away from Paul to pay Peter.

Further, the sad news does not stop here. The deleterious effects of the prospective payment for hospital outpatient services are only beginning to surface. The rule released on April $7^{\text {th }}, 2000$, and which is expected to be implemented August 1, 2000, is already showing its effect (6, 79). As per this rule, hospital payments for many pain management services have been drastically reduced. This ranges from $\$ 102$ for trigger point injections, and various types of joint injections to $\$ 161$ for transforaminal cervical, thoracic, lumbar and sacral epidurals, lumbar and cervical facet injections, as well as facet neurolysis and various other types of nerve blocks; $\$ 176$ for percutaneous epidural adhesiolysis, cervical and thoracic, lumbar and caudal epidural injections; $\$ 245$ for epidurography; no reimbursement for SI joint injection, cervical, thoracic or lumbar discography; $\$ 773$ for implantation of neurostimulator, pulse generator or removal of these; and, finally $\$ 1235$ for implantation or replacement of drug infusion reservoir programmable or nonprogrammable pump. While implementation is not scheduled until August $1^{\text {st }}$, fireworks have already started. In a recent newsletter for anesthesiologists (80), the heading read "OPPS: No More Outpatient Pain Injections?" It went on to say:

Pain practitioners working in outpatient clinics may find themselves opening private pain clinics soon. That was the consensus of Anesthesia practice managers at the AAA meeting. Hospitals' facility fees under the new OPPS will be so low, some "will tell pain groups, 'don't bring your work here'.

In a "dear colleague" letter, Roberta L. Hines, Professor and Chairman, J. Steven Naulty, Medical Director, Center for Pain Management, Yale University School of Medicine, Department of Anesthesiology, described the closure of the Center for Pain Management, effective June 30, 2000 (81). They stated:

As you are aware, the present health care environment is a challenging and dynamic one. Recent changes in the fiscal aspects of pain management services have forced the department to close the Center for Pain Management, effective June 30, 2000. This has been a difficult but necessary step. I can assure you that this move was not taken without exploring all alternative options for fiscal support.

Additionally, onerous medicare regulations are being implemented at an exponential rate. Under these regulations, physician autonomy is being lost. These regulations significantly limit or even curtail choices of interventional pain procedures. The most recent example of such regulations is the classification of percutaneous lysis of adhesions as an investigational procedure by many medicare intermediaries . This, in spite of the fact that HCFA central's review of the problem resulted in the as- 
signment of a new code and relative value.

It appears that we may be looking at more of these in the near future once hospital outpatient department prospective payment rule and final ambulatory surgery rule hits the interventional pain specialists and providers of hospital and ambulatory surgical center services.

So what needs to be done, and how can it be achieved? Following the precedent of AMA, which asks physicians: "While you are looking out for your patients, who is looking out for you?" I would like to ask interventional pain physicians: "While you are complaining and worried about regulations and taking care of your patients, who is looking out for your interests?" It is the responsibility of each and every interventional pain physician to not only represent the interests of interventional pain medicine, but also promote these interests, as is done by almost every other specialty, including behavioral pain specialists. At this time, all interventional pain specialist should ask themselves what their societies are doing for them and what they can do to improve the state of the affairs of interventional pain medicine. As executive director and president of AOPMA, I believe that interventional pain physicians are strong but fragmented, and therefore appear weak. Interventional pain medicine specialists often forget their interests and loyalties, which leads to factions and fighting, mainly due to a lack of knowledge of the present-day state of affairs and, in certain circumstance, inflated egos. As a group, we interventional pain medicine physicians must not only unite, but show a strong force with the one and only goal of preserving the specialty of interventional pain medicine. Of course, to achieve this goal, we need recognition for interventional pain medicine as a specialty, appropriate reimbursement for practice expenses, preservation of the procedures to be performed in ambulatory surgery centers, and clear delineation and guidelines to incorporate interventional pain procedures in the clinical management of patients suffering with chronic pain.

\section{REFERENCES}

1. Manchikanti L. Interventional pain physician. What's in a name? Pain Physician 2000; 3:132-138.

2. Morris DB. An invisible history of pain: Early $19^{\text {th }}$ century Britain and America. Clin J Pain 1998; 191196.

3. Manchikanti L. CPT 2000: Interventional pain management coding in the new millennium. Pain Physician 2000; 3:73-85.

4. Current procedural terminology, CPT 2000, Chicago,
American Medical Association, 1999.

5. Revisions to payment policies under the physician fee schedule for Calender year 2000. Final rule. 64 Federal Register, 59389, November 2, 1999.

6. Medicare Program Prospective Payment System for Hospital Outpatient Services; Final Rule: Department of Health and Human Services. Health Care Financing Administration 42 CFR Parts 412, 413, and 485.

7. Robechhi A, Capra R. L'idrocortisone (composto F). Prime esperienze cliniche in campo reumatologico. Minerva Med 1952; 98:1259-1263.

8. Lievre JA, Bloch - Michel H, Pean G et al. L'hydrocortisone en injection locale. Rev Rhum 1953; 20:310-311.

9. Biella A, Cicognini P. L'acetato di idrocortisone nel trattamento della sindrome sciatalgica. Minerva Med $1954 ; 1: 1863-1865$.

10. Canale L. Il desametazone per via epidurale sacrale nelle lombosciatalgie. Gaz Med Ital 1963; 122:210213.

11. Cappio M. Il trattamento idrocortisonico per via epidurale sacrale delle lombosciatalgie. Reumatismo 1957; 9:60-70.

12. Cappio M, Fragasso V. Osservazioni sull'uso dell'idrocortisone per via epidurale ed endorachidea nelle lombosciatalgie. Riforma Med 1955; 22:605607.

13. Cappio M, Fragasso V. Il prednisolone per via epidurale sacrale nelle lombosciatalgie. Reumatismo 1957; 5:295-298.

14. Fragasso V. Il prednisolone idrosolubile per via epidurale sacrale nelle lombosciatalgie. Gaz Med Ital $1959 ; 118: 358-360$.

15. Gerest MF. Le traitement de la nevralgie sciatique par les injections epidurales d'hydrocortisone $\mathrm{J} \mathrm{Med}$ Lyon 1958; 261-264.

16. Gilly R. Essai de traitement de 50 cas de sciatiques et de radiculalgies lombaires par le Celestene chronodose en infiltrations pararadiculaire. Marseille Medicale 1970; 107:341-345.

17. Renier JC. L'infitration epidurale par le premier trou sacre posterieur. Revue du Rhumatisme et des Maladies Osteo - articulaire 1959; 26:526-532.

18. Manchikanti L, Singh V, Bakhit C et al. Interventional techniques in the management of chronic pain: Part 1.0. Pain Physician 2000: 3:7-42.

19. Manchikanti L. The role of neural blockade in the management of chronic low back pain. Pain Digest 1999; 9:166-181.

20. Bogduk N, Christophidis N, Cherry De et al. Epidural use of steroids in the management of back pain. Report of working party on epidural use of steroids in the management of back pain. National Health and Medical Research Council. Canberra, Commonwealth of Australia, 1994; pp 1-76.

21. White AH, Derby R, Wynne G. Epidural injections for diagnosis and treatment of low back pain. Spine 
1980; 5:78-86.

22. Fredman B, Nun MB, Zohar E et al. Epidural steroids for treating "failed back surgery syndrome": Is fluoroscopy really necessary? Anesth Analg 1999; 88:367-372.

23. Mehta M, Salmon N. Extradural block. Confirmation of the injection site by X-ray monitoring. Anaesthesia 1985; 40:1009-1012.

24. Burn JM, Guyer PB, Langdon L. The spread of solutions injected into the epidural space: A study using epidurograms in patients with lumbosciatic syndrome. Br J Anaesth 1973: 45:338-345.

25. Nishimura N, Khahara T, Kusakabe T. The spread of lidocaine and 1-131 solution in the epidural space. Anesthesiology 1959; 20:785-788.

26. Carette S, Lecaire R, Marcoux S et al. Epidural corticosteroid injections for sciatica due to herniated nucleus pulposus. N Engl J Med 1997; 336:16341640.

27. Hodgson PSA, Mack B, Kopacz D et al. Needle placement during lumbar epidural anesthesia deviates toward the non-dependent side (abstract). Reg Anesth 1996; 21:26.

28. Bromage RP, Benumof JL. Paraplegia following intracord injection during attempted epidural anesthesia under general anesthesia. Reg Anesth and Pain Med 1998; 23:104-107.

29. Krane EJ, Dalens BJ, Murat I et al. The safety of epidurals during general anesthesia. Reg Anesth and Pain Med 1998; 23:433-438.

30. Saberski LR, Kondamur S, Osinubi OYO. Identification of the epidural space: Is loss of resistance to air a safe technique? Regional Anesthesia 1997; 22:315 .

31. Manchikanti L, Bakhit CE, Pampati V. Role of epidurography in caudal neuroplasty. Pain Digest 1998; 8:277-281.

32. Renfrew DL, Moore TE, Kathol MH et al. Correct placement of epidural steroid injections: Fluoroscopic guidance and contrast administration. Amer $J$ Neuroradiol 1991; 12:1003-1007.

33. Stewart HD, Quinnell RC, Dann N. Epidurography in the management of sciatica. Br J of Rheum 1987; 26:424-429.

34. El-Khoury G, Ehara S, Weinstein JW et al. Epidural steroid injection: A procedure ideally performed with fluoroscopic control. Radiology 1988; 168:554-557.

35. Stitz MY, Sommer HM. Accuracy of blind versus fluoroscopically guided caudal epidural injection. Spine 1999; 24:1371-1376.

36. Tajima T, Furukawa K, Kuramocji E. Selective lumbosacral radiculography and block. Spine 1980; 5:6877.

37. Manchikanti L, Pakanati RR, Pampati V. Comparison of three routes of epidural steroid injections in low back pain. Pain Digest 1999; 9:277-285.

38. Derby R, Kine G, Saal JA et al. Response to steroid and duration of radicular pain as predictors of surgical outcome. Spine 1992; 17(Suppl):176-183.

39. Weiner BK, Fraser RD. Foraminal injection for lateral lumbar disc herniation. J Bone Joint Surg 1997; 79-B:804-807.

40. Devulder J. Transforaminal nerve root sleeve injection with corticosteroids, hyaluronidase, and local anesthetic in the failed back surgery syndrome. $J$ Spinal Disord 1998; 11:151-154.

41. Lutz GE, Vad VB, Wisneski RJ. Fluoroscopic transforaminal lumbar epidural steroids. An outcome study. Arch Phys Med Rehabil 1998; 79:1362-1366. Slipman CW, Plastaras CT, Palmitier RA et al. Symptom provocation of fluoroscopically guided cervical nerve root stimulation. Are dynatomal maps identical to dermatomal maps? Spine 1998; 23:2235-2242.

43. Lutz GE, Vad VB, Wisneski RJ. Fluoroscpoic transforaminal lumbar epidural steroids. An outcome study. Presented at ISIS $7^{\text {th }}$ Annual Scientific Meeting, Las Vegas, Nev. August 1999.

44. Riew KD, Yin Y, Gilula L et al. Can nerve root injections obviate the need for operative treatment of lumbar radicular pain? A prospective, randomized, controlled, double-blind study. Proceedings of North American Spine Society $16^{\text {th }}$ Annual Meeting, Chicago. 1999; 94-95.

45. Hodges SD, Castleberg RL, Miller T et al. Cervical epidural steroid injection with intrinsic spinal cord damage. Two case reports. Spine 1998; 23:2137-2142.

46. Derby R. Point of view. Spine 1998; 23:2141-2142.

47. Manchikanti L. Epidural steroid injections and intrinsic spinal cord damage. Spine 1999; 24:1170-1171.

48. Manchikanti L. Neural blockade in cervical pain syndromes. Pain Physician 1999; 3:65-84.

49. Bogduk N, Marsland A. The cervical zygapophyseal joints as a source of neck pain. Spine 1988; 13:610617.

50. Bogduk N, Marsland A. On the concept of third occipital headache. J Neurol Neurosurg Psychiatry 1986; 49:775-780.

51. Sluijter ME, Koetsveld-Baart CC. Interruption of pain pathways in the treatment of cervical syndrome. Anaesthesia 1980; 35:302-307.

52. Dwyer A, Aprill C, Bogduk N. Cervical zygapophyseal joint pain patterns: A study in normal volunteers. Spine 1990; 15:453-457.

53. Fukui S, Ohseto K, Shiotani M et al. Referred pain distribution of the cervical zygapophyseal joints and cervical dorsal rami. Pain 1996; 68:79-83.

54. Bogduk N, Aprill C. On the nature of neck pain, discography, and cervical zygapophyseal joint blocks. Pain 1993; 54:213-217.

55. Barnsley L, Lord SM, Wallis BJ et al. The prevalence of chronic cervical zygapophyseal joint pain after whiplash. Spine 1995; 20:20-26.

56. Lord SM, Barnsley L, Wallis BJ et al. Chronic cervical zygapophysial joint pain with whiplash: A pla- 
cebo-controlled prevalence study. Spine 1996; 21:17371745 .

57. Bogduk N. International spinal injection society guidelines for the performance of spinal injection procedures. Part 1: Zygapophyseal joint blocks. Clin J Pain 1997; 13:285-302.

58. Hildebrandt J, Argyrakis A. Percutaneous nerve block of the cervical facets - a relatively new method in the treatment of chronic headache and neck pain. Man Med 1986; 2:48-52.

59. Dory MA. Arthrography of the cervical facet joints. Radiology 1983; 148:379-382.

60. Barnsley L, Bogduk N. Medial branch blocks are specific for the diagnosis of cervical zygapophyseal joint pain. Reg Anesth 1993; 18:343-350.

61. McCormick CC. Arthrography of the Atlanto-Axial (C1-C2) joints: Technique and results. J Intervent Radiol 1987; 2:9.

62. Lord SM, Barnsley L, Wallis BJ et al. Third occipital nerve headache. A prevalence study. J Neurol NeuroSurg Psychiatry 1994; 57:1187-1190.

63. Rasmussen BK, Jensen R, Schroll M et al. Epidemiology of headache in a general population - A prevalence study. J Clin Epidemiol 1991; 44:1147-1157.

64. Kuslich SD, Ulstrom CL, Michael CJ. The tissue origin of low back pain and sciatica: A report of pain response to tissue stimulation during operation on the lumbar spine using local anesthesia. Orthop Clin North Am 1991; 22:181-187.

65. Aprill C, Dwyer A, Bogduk N. The prevalence of cervical zygapophyseal joint pain patterns II: A clinical evaluation. Spine 1990; 15:458-461.

66. Dreyfuss P, Michaelsen M, Fletcher D. Atlanto-Occipital and lateral Atlanto-Axial joint pain patterns. Spine 1994; 19:1125-1131.

67. Wallis BJ, Lord SM, Bogduk N. Resolution of psychological distress of whiplash patients following treatment by radiofrequency neurotomy: A randomized, double-blind, placebo-controlled trial. Pain 1997; 73:15-

68. Schaerer JP. Treatment of prolonged neck pain by radiofrequency facet rhizotomy. J Neurol Orthop Med
Surg 1988; 9:74-76.

69. Vervest ACM, Stolker RJ. The treatment of cervical pain syndromes with radiofrequency procedures. Pain Clinic 1991; 4:103-112.

70. Schaerer JP. Radiofrequency facet rhizotomy in the treatment of chronic neck and low back pain. Int Surg 1978; 63:53-59.

71. Lord SM, Barnsley L, Wallis BJ et al. Percutaneous radio-frequency neurotomy for chronic cervical zygapophyseal-joint pain. N Eng J Med 1996; 335:1721-1726.

72. Roy DF, Fleury J, Fontaine SB et al. Clinical evaluation of cervical facet joint infiltration. J Can Assoc Radiol 1988; 39:118-120.

73. Manchikanti L, Bakhit CE. Percutaneous lysis of epidural adhesions. Pain Physician 2000; 3:46-64.

74. Racz GB, Holubec JT. Lysis of adhesions in the epidural space. In: Racz GB (ed). Techniques of neurolysis. Boston, Kluwer Academic, 1989; 57-72.

75. Arthur J, Racz G, Heinrich R et al. Epidural space. Identification of filling defects and lysis of adhesions in the treatment of chronic painful conditions. In: Abstracts, $7^{\text {th }}$ World Congress on Pain. Paris, IASP Publications, 1993, pp 557.

76. Manchikanti L, Pakanati R, Bakhit CE et al. Role of adhesiolysis and hypertonic saline neurolysis in management of low back pain. Evaluation of modification of Racz protocol. Pain Digest 1999; 9:91-96.

77. Racz GB, Heavner JE, Raj PP. Percutaneous epidural neuroplasty. Prospective one-year follow up. Pain Digest 1999; 9:97-102.

78. Heavner JE, Racz GB, Raj PP. Percutaneous epidural neuroplasty. Prospective evaluation of $0.9 \% \mathrm{NaCl}$ versus $10 \% \mathrm{NaCl}$ with or without hyaluronidase. Reg Anesth Pain Med 1999; 24:202-207.

79. Pain Physician News, Association of Pain Management Anesthesiologists, April 2000.

80. Anesthesia Answer Book Action Alert, UCG, Rockville, Maryland, May 2000; pp. 2-3.

81. Hines RL, Naulty JS. Letter to Colleagues, Yale University School of Medicine, Department of Anesthesiology, May $16^{\text {th }}, 2000$. 